\title{
Sobre Dewey, jogos digitais e ensino de História
}

\author{
On Dewey, digital games and History teaching
}

\section{Sobre Dewey, juegos digitales y enseñanza de Historia}

\author{
Stella Maria Peixoto de AZeVedo Pedrosa (iDa
}

KaUAN PESSANHA-SOARES (Db

\section{Resumo}

O artigo associa a filosofia progressista de John Dewey, talvez o mais influente filósofo da educação no século XX, às concepções de jogos digitais e ao processo ensino-aprendizagem da História, considerando o jogo como uma possibilidade para o ensino dos conteúdos curriculares desta disciplina. Dewey defendeu a afinidade de todo conhecimento com o conhecimento prévio e, em termos historicistas, via a disciplina História como um produto do desenvolvimento histórico. Em sua perspectiva, para a compreensão de qualquer porção do conhecimento e sua relação com um indivíduo ou sociedade, deve-se entender sua história e, nesse sentido, considera o currículo organizado como uma história reencenada e cuidadosamente selecionada. Deste modo, os jogos digitais podem contribuir para o ensino dos conteúdos curriculares de História, visto que muitas de suas temáticas envolvem, de forma lúdica, importantes fatos históricos da humanidade, proporcionando o contato e ampliando o interesse pelo conhecimento histórico. Sob o enfoque deweyano, buscando-se integrar a "vida real" com as atividades escolares, discute-se de que modo os jogos digitais podem colaborar para que suas narrativas sejam relacionadas ao processo de ensinoaprendizagem. Em síntese, no artigo a perspectiva de Dewey é relacionada às concepções de jogos digitais e ao ensino da História, sendo, o jogo apresentado como uma possibilidade para a aprendizagem da História.

Palavras-chave: Dewey. História. Jogos digitais. Aprendizagem. Escola.

\footnotetext{
a Universidade Estácio de Sá (UNESA), Rio de Janeiro, RJ, Brasil. Doutora em Educação, e-mail: smpedrosa@gmail.com

b Universidade Estácio de Sá (UNESA), Rio de Janeiro, RJ, Brasil. Mestre em Educação, e-mail: kauanpessanha@gmail.com
} 


\section{Abstract}

The article associates the progressive philosophy of John Dewey, perhaps the most influential philosopher of education in the twentieth century, with the conceptions of digital games and the teaching-learning process of History, considering the game as a possibility for teaching the curricular contents of this subject. Dewey defended the affinity of all knowledge with prior knowledge and, in historicist terms, viewed History as a product of historical development. In his perspective, to understand any portion of knowledge and its relation to an individual or society, one must understand its history and, in this sense, considers the organized curriculum as a reenacted and carefully selected story. Thus, digital games can contribute to the teaching of curricular contents of History, since many of its playful themes involve important historical facts of humanity, providing contact and increasing interest in historical knowledge. In Dewey's approach, seeking to integrate "real life" with school activities, it is discussed how digital games can collaborate to the fact that their narratives are related to the teaching-learning process. In summary, in the article, Dewey's perspective is related to the conceptions of digital games and the teaching of History, being, the game presented as a possibility for the learning of History.

Keywords: Dewey. History. Digital games. Learning. School.

\section{Resumen}

El artículo asocia la filosofía progresista de John Dewey, tal vez el más influyente filósofo de la educación en el siglo XX, a las concepciones de juegos digitales y al proceso enseñanza-aprendizaje de la Historia, considerando el juego como una posibilidad para la enseñanza de los contenidos curriculares de esta disciplina. Dewey defendió la afinidad de todo conocimiento con el conocimiento previo y, en términos historicistas, a través de la disciplina Historia como un producto del desarrollo histórico. En su perspectiva, para la comprensión de cualquier porción del conocimiento y su relación con un individuo o sociedad, se debe entender su historia y, en ese sentido, considera el currículo organizado como una historia reencenada y cuidadosamente seleccionada. Asimismo, los juegos digitales pueden contribuir a la enseñanza de los contenidos curriculares de Historia, ya que muchas de sus temáticas involucran, de forma lúdica, importantes hechos históricos de la humanidad, proporcionando el contacto y ampliando el interés por el conocimiento histórico. Bajo el enfoque deweyano, logrando integrar la "vida real" con las actividades escolares, se discute de qué modo los juegos digitales pueden colaborar para que sus narrativas estén relacionadas al proceso de enseñanza-aprendizaje. En síntesis, el artículo relaciona la perspectiva de Dewey a las concepciones de juegos digitales y a la enseñanza de la Historia, siendo el juego presentado como una posibilidad para el aprendizaje de la disciplina.

Palabras clave: Dewey. Historia. Juegos digitales. Aprendizaje. Escuela. 


\section{Introdução}

A filosofia progressiva de John Dewey, um dos mais influentes filósofos da educação no século XX, pode contribuir com fundamentos teóricos para o uso de jogos digitais em sala de aula. Para ele, as técnicas educacionais tradicionais são responsáveis por uma separação artificial entre a escola e a "vida real", o que sufoca a criatividade dos alunos e qualquer possibilidade de aprendizagem.

Dewey defendia a afinidade de todo o conhecimento a um conhecimento prévio. Nas obras "Reconstrução em Filosofia" (1958) e "Democracia e Educação" (1959), ele aborda elementos importantes sobre a História. Compreendia-a como um produto do desenvolvimento histórico. Nessa perspectiva, a história não tem um significado estático, ao contrário, o seu significado evolui tal como a humanidade e, por conseguinte, também progride para um indivíduo quando ele revive a história da humanidade.

Segundo Dewey (1959), para entender qualquer porção de conhecimento e sua relação a um indivíduo ou sociedade, é preciso compreender a sua história e, neste sentido, considera o currículo organizado como uma história cuidadosamente selecionada e reencenada.

Neste artigo, relacionamos a perspectiva de Dewey com as concepções de jogos digitais e o ensino de História. Consideramos o jogo como estratégia didática para o ensino dos conteúdos curriculares de História, visto que, com a popularização dos chamados consoles, enredos e temáticas dos jogos digitais voltados para importantes fatos históricos da humanidade presentes de forma lúdica, o contato e a curiosidade sobre temáticas históricas são ampliadas. Desse modo, acreditamos ser viável discutir como esta tecnologia pode contribuir para que as narrativas de jogos possam ser relacionadas aos conteúdos curriculares de História.

\section{Sobre John Dewey}

John Dewey (1859-1952) foi um filósofo e pedagogo norte-americano, cuja obra influenciou educadores de diferentes países e de várias áreas da educação: ensino, 
filosofia da educação, psicologia educacional e política educacional. Um dos educadores mais influentes do século XX, e considerado um ativista político, Dewey demonstrou seu compromisso prático, moral e cívico por meio de suas obras e suas criações institucionais nas áreas em que trabalhou nas Universidades de Chicago e Columbia (RUIZ, 2013).

No Brasil, as ideias de Dewey repercutiram, especialmente, em dois momentos marcantes na História da Educação do país. O primeiro, em 1932, no Movimento dos Pioneiros da Escola Nova, que teve em Anísio Teixeira — seu ex-aluno, tradutor de suas obras para a língua portuguesa — o principal difusor de suas ideias. O segundo momento, durante o período de redemocratização brasileira, nos anos de 1990, que teve como foco os pressupostos voltados para a formação de professores. Conforme Souza e Martinelli (2009), as principais abordagens eram voltadas para a "Epistemologia da Prática Reflexiva" ou corrente do "Professor Reflexivo", propostas que discutiam a formação inicial e continuada em diversos países.

Dewey (1933) diferencia o "ato rotineiro" e o "ato reflexivo". O primeiro estaria relacionado ao não questionamento, à aceitação passiva das ordens recebidas à acriticidade, enquanto o segundo teria como base o questionamento e, a partir das crenças particulares, uma solução lógica e racional seria encontrada para os problemas.

Dewey (1959) observou que o sistema educacional de seu país utilizava técnicas tradicionais de ensino que concebiam o conhecimento como uma mercadoria monolítica e imutável. Ele concluiu que, devido à crença dos educadores tradicionais na verdade absoluta dos fatos, eles adotavam métodos que incentivavam a memorização dos mesmos.

A filosofia progressiva de Dewey (1959) opõe-se à valorização da obediência significativamente presente na educação tradicional, pois considera o constante crescimento à medida em que o conteúdo é desenvolvido com a participação do aluno. Nesse sentido, a experiência é uma determinante importante, pois as percepções das relações e continuidades presentes em um período histórico necessitam de aporte cognitivo. Este aporte deve ser estruturado para que se possa associar os elementos dos fatos históricos, da percepção do indivíduo e da reflexão 
cognitiva gerada a partir do que foi trabalhado com o aluno. Essa postura favorece a fundamentação teórica para o uso de jogos digitais em sala de aula.

\section{O contexto histórico da filosofia de Dewey}

Dewey viveu em um período de significativas mudanças políticas e sociais e transformações no sistema de produção, fatos esses que influenciaram consideravelmente suas posições acadêmicas e políticas.

Ruiz (2013) relaciona as características do processo de mobilidade social ascendente nos EUA com a mobilidade das fronteiras que, no século XIX, levou os pioneiros a desbravarem um extenso território a ser colonizado. Os pioneiros foram encorajados pela sua fé na experiência humana como um meio para a mudança. Isto resultou em uma estratificação social flexível, contexto no qual as pessoas são mais valorizadas pelas competências do que pelas origens familiares.

Souza e Machado (2009, p. 105) destacam a importância do contexto histórico em que foi desenvolvida a Pedagogia de Dewey. A partir dos meados do século XIX, os Estados Unidos viveram um "período de transição da hegemonia para a crise do capitalismo industrial" que, em 1929, resultou na "quebra" da bolsa de Nova Iorque.

Esse evento mergulhou o país de Dewey em uma profunda crise econômica. Além disso, Dewey assistiu às duas grandes guerras mundiais do século XX. Temos o surgimento de novas ciências como: a sociologia, a psicologia e a biologia. Esses elementos marcaram decisivamente a pedagogia de Dewey (SOUZA; MACHADO, 2009, p. 105).

No século XIX, a sociedade tinha perfil desafiador e aberto à mudança, o que permeou o pensamento e a prática de Dewey. Na perspectiva dos tempos futuros, em função daquele em que viveu, ele se comprometeu com a ideia de realizar uma reforma social e educacional. Sob seu ponto de vista, a reforma educacional de Dewey foi compreendida como um empreendimento coletivo, não como um trabalho individual (RUIZ, 2013). Foi com essa expectativa que Dewey adotou o pragmatismo, corrente filosófica desenvolvida nos Estados Unidos.

Na perspectiva pragmática de Dewey (1959), o conhecimento pode ser visto como um ato de experiência e a realidade, experimentada. Sob o ponto de vista educacional de Dewey, isso se traduz na necessidade de os alunos interagirem com 
seu meio ambiente, com o objetivo de adaptação e aprendizagem. Esse mesmo conceito impõe-se às ações dos professores, que devem “aprender" juntamente com os alunos, a partir de experiências práticas.

Ele apresentou ideias e abordagens consideradas revolucionárias e essenciais para a escola. Em suas obras, ressaltou o valor da educação progressiva, destacando a necessidade do learn by doing (aprender fazendo). Na concepção deweyana de democracia, evidente em sua obra "Democracia e Educação" (DEWEY, 1959), a escola é tida como um espaço de experimentação democrática para a formação do cidadão, o que se traduz em local voltado ao aprendizado dos valores cívicos e republicanos, por meio da experimentação dos mesmos.

Para ele, as escolas deveriam ser instrumentos de democratização, uma tarefa colossal, sem dúvida, pois “o sistema escolar sempre esteve em função do tipo de organização da vida social dominante” (DEWEY, 1896; apud BRESOLIN, 2011, p. 42).

Dentre as inúmeras críticas recebidas por Dewey, destaca-se a de seu posicionamento em relação à escola, vista como "uma instituição apolítica, desvinculada do restante da sociedade e que pudesse funcionar como um oásis democrático" (BRESOLIN, 2011, p. 42), entretanto, revendo seus posicionamentos, Dewey "assume que sua proposta de fazer educação não poderia ser aplicada em situações onde houvesse relação de poder ou desigualdade democrática" (BRESOLIN, 2011, p. 42).

Dewey destaca a importância do envolvimento do aluno em atividades significativas, ou seja, em uma ação que faça sentido para eles. De acordo com Ruiz (2013, p. 122, tradução nossa), a teoria de Dewey permanece de várias formas nas tendências educacionais contemporâneas, em aspectos tais como:

- a valoração positiva da aprendizagem por descoberta.

- assim se promove a incorporação entre os conteúdos de ensino de objetos manipuláveis e visitas a museus, para citar dois exemplos, como estratégias para estimular a exploração dos estudantes.

- a promoção e incorporação do debate entre os dispositivos didáticos em todos os níveis de ensino.

- a inclusão dos meios e atividades para que os estudantes trabalhem em projetos individuais ou em grupos.

- a atenção aos resultados dos estudos empíricos sobre a aprendizagem, o desenvolvimento e a motivação das crianças. 
- o ajuste do ensino e dos currículos para que se adaptem aos resultados de investigação.

- a concepção do docente não como uma autoridade se não como um facilitador das aprendizagens, como a fonte de melhores recursos, como o forjador do entorno no qual os estudantes aprenderão.

\section{A história na concepção deweyana}

Dewey via a disciplina de História como um produto do desenvolvimento histórico (DEWEY, 1959). O passado apenas tem significado quando este lhe é atribuído ou quando enquadrado em uma narrativa particular no presente. Sob o viés do ensino de História, Dewey relacionava todo conhecimento a um conhecimento prévio e, na perspectiva de psicólogo especializado em aconselhamento, considerava qualquer afirmação histórica arraigada de acepções contextuais, organizadas por fases distintas da consciência. Assim, a História não tem um significado estático, ao contrário, evoluiu tal como a humanidade avança e, por conseguinte, seu significado progride para um indivíduo quando ele revive a história da humanidade.

Como uma ciência que estuda os acontecimentos na história humana, uma das críticas de Dewey $(1958,1959)$ ao método de ensino da história relaciona-se às premissas dogmáticas com as quais o ensino ocorria na maior parte das instituições daquele período. As metodologias embasadas em modelos fabris, na forte memorização de conteúdos e matérias desconexas do conteúdo social deveria ser revista. $\mathrm{Na}$ concepção do filósofo, a escola era a vida e não uma preparação para a vida, ou seja, o engajamento na premissa de uma educação democrática exigia uma estrutura que proporcionasse aos alunos e professores oportunidades de estarem engajados ativamente na prática da democracia.

Para ele, segundo Bresolin (2011, p. 43), o professor "deveria ser alguém que refletisse sobre sua prática constantemente, na esperança que isso trouxesse de maneira natural, o desenvolvimento de seu pensamento e de suas ações".

A teorização dos conteúdos possui sua relevância e traz consigo importantes componentes para embasar uma ação a ser desenvolvida. Necessariamente, conhecer as regras do jogo e localizar-se nos contextos que envolvem uma ação é relevante. Em especial, quando os conteúdos são trabalhados com outras ciências, um aporte teórico faz-se imprescindível para alicerçar uma prática ou investigar as causas da falha de 
uma atividade. Dewey (1978) afirma que para a experiência seja educativa, deve conduzir a um mundo de matérias permeadas de fatos e informações, ou seja, com ideias que são reconstruídas de acordo com a execução prática.

Inevitavelmente, dentro de uma sala de aula, as ciências necessitam dialogar entre si; e não poderia ser diferente. O que erroneamente ocorre é o desenvolvimento de uma visão isolada de cada disciplina, desconectada de algo factual, impossibilitando uma análise por outros campos da ciência. Isto fatalmente reduz as chances de os alunos visualizarem uma disciplina ou matéria curricular, sem uma análise a priori de seu respectivo campo teórico e de sua devida potencialidade, limitando seu campo de conhecimentos e associações de um saber.

A pedagogia de Dewey baseia suas ações em fins práticos. Vivenciar o passado, compreender e valorizar os períodos presentes e valorizar os feitos de cada sociedade são elementos significativos de serem alvo em atividades com os alunos. Sem dúvida, no processo de aprendizagem é relevante considerar os diferentes contextos para que se compreenda a história de qualquer sociedade.

Segundo Dewey (1959), para a compreensão e o consequente desenvolvimento do conhecimento histórico, bem como sua relação com indivíduos e/ou sociedades, é preciso perceber o passado. Analisar os fatos em separado, como o passado se encerrasse em um ciclo, desvinculado com o presente, impossibilita essa compreensão, pois a existência humana não se configura em ciclos fechados em si mesmos, sem que uma etapa esteja impossibilitada de acesso à seguinte.

Desse modo, a vida e o aprendizado podem ser compreendidos como processos comparáveis que tiram proveito de experiências anteriores para a construção de conhecimentos, seja de modo individual ou coletivo. Oelkers (2018, p. 10) afirma que sob o ponto de vista de Dewey,

a sociedade não é uma 'coisa' ou um 'corpus', mas uma interação complexa entre indivíduos e grupos. Todas as instituições ou processos sociais são soluções para problemas, que podem ser alterados em face de novos problemas e novas soluções.

Como muitos de seus contemporâneos, Dewey concordava que uma teoria de mudança histórica seria a chave para a compreensão do presente. As grandes ciências do século XX foram as ciências históricas e sociais, tomadas a partir de um ponto de 
vista que buscasse uma visão mais aproximada dos contextos, diferentemente de uma história contemplativa, de feitos militares ou de grandes personalidades.

As dimensões de estudo da história, influenciadas particularmente pelo movimento da Escola dos Annales ${ }^{1}$, traria a valorização de importantes elementos, tais como a preocupação com o cotidiano das pessoas, a busca de novas fontes de estudo e da pesquisa histórica, questionamento de documentos, valorizando os vestígios dos fatos e não necessariamente seu retrato fidedigno e legitimado.

Barros (2010, p. 5) analisa a base historiográfica para que a perspectiva dos Annales pudesse se consolidar e traz as perspectivas que influenciariam muitos dos estudos históricos ao longo do século XX:

Os Annales, em busca de sua conquista territorial da História, precisavam enfrentar as tendências historiográficas então dominantes, mas também se afirmar contra uma força nova que começava a trazer métodos e aportes teóricos inovadores para o campo do conhecimento humano: as nascentes Ciências Sociais. É contra o pano de fundo deste duplo desafio que o movimento inicia a sua aventura historiográfica.

A possibilidade de novas fontes de estudos e de tempo histórico demandaria uma nova compreensão sobre métodos de pesquisa, nas multiplicidades das abordagens nas quais a análise do tempo não seria o suficiente para responder. Seria necessário pensar sobre os sujeitos não descritos ou parcialmente apresentados na história, levando-se em conta os elementos sociais e as histórias cotidianas como fonte.

Da mesma forma, a história seria a chave para conceituar o âmbito e a sequência do currículo escolar.

Enquanto imanente aos processos objetivos, o tempo histórico revela antes sua pluralidade, sua multiplicidade, a sua descontinuidade, as suas assimetrias, as suas irreversibilidades particulares e jamais a unidade total. Não se tem mais a unidade, mas a diversidade (REIS, p. 31).

\footnotetext{
${ }^{1}$ Anteriormente, o paradigma tradicional do estudo da história restringia-se ao apresentado sob o viés político o qual, de acordo com Peter Burke (1992), foi criticado na obra La nouvelle histoire, uma coleção de ensaios editada pelo medievalista francês Jacques Le Goff. A chamada École des Annales, agrupada em torno da revista Annales: économies, societés, civilisations, marca a "nova história" que começou a se interessar amplamente por toda atividade humana, considerando para o estudo da história elementos como economia, sociedade, entre outros.
} 
Pensar em um currículo escolar torna-se uma atribuição complexa, pois na construção é importante considerar elementos capazes de incentivar ao questionamento sobre as fontes, análise sobre os fatos e a participação do sujeito nos processos históricos. Materializar um evento histórico ocorrido ou criar as noções de participação como sujeito ativo de uma história presente são alguns dos desafios mais importantes de se concretizar ao estudar a História.

Garcia (2010) explica que é possível classificar o currículo de duas formas. A primeira, como artefato escolar, no qual as concepções de currículo estão relacionadas com o campo de aprendizagem ofertado aos alunos. Já a segunda, vista como um campo de disputas e debates. Segundo Silva (2012), compreende-se o currículo como a forma pela qual se define as intencionalidades educacionais, ou seja, assumindo assim, como um elemento de mediação entre professores e alunos em conjunto com o conhecimento.

Dewey (1959) identificou como um problema da educação estabelecer conexões vitais entre a criança (por sua imaturidade) e as realizações culturais e técnicas da vida adulta. Assim, considerou que o aumento contínuo da dificuldade nas tarefas propostas seria uma forma de reduzir as dificuldades na compreensão de um conteúdo. Para tal, é necessário um currículo apropriado, que disponibilize mecanismos para a introdução de relações de participação e pertencimento, e à construção de saberes de modo lúdico, adequado às realidades dos alunos. Desse modo, proporcionando vivências com capacidade de ensinar o conhecimento humano com a experiência social, que possam conduzir à construção de saberes e habilitem ao fluxo de vivências subsequentes.

De acordo com Dewey (1959), o estudo da História deve introduzir a criança a uma consciência da composição ou estrutura da vida social, bem como dar-lhe o comando sobre os instrumentos por meio dos quais a sociedade realiza-se ao longo do tempo. O primeiro é o valor do conteúdo, o segundo é o valor da forma.

O conteúdo da história, ou seja, os fatos, determina a forma da história, por outro lado, a forma da história, que institui o método, produz conteúdo. Portanto, por meio de um estudo do conteúdo da história é que os alunos conheçam como e porque o método histórico surgiu. Assim, os alunos poderão perceber que a história 
pode ser averiguada por diferentes meios: relatos, documentos (distinguindo que fontes primárias e secundárias), estudos arqueológicos, entre outras possibilidades.

Desse modo, a compreensão do processo de investigação para a construção de um saber histórico pode significar o (re)conhecimento do papel relevante da investigação e dos elementos que podem levar à construção de indícios e vestígios, o que contribui para a contextualização do conteúdo aprendido na escola com o cotidiano. Além disso, o conteúdo da História abordado nas aulas, é, em si próprio, produto do método histórico. Ambos, conteúdo e método, são relevantes para o aprendizado.

Nessa perspectiva, de acordo com os recursos disponíveis, são muitas as atividades que podem contribuir para a abordagem de conteúdos de História. Como exemplo, podem ser citadas: realização de visitas guiadas a locais históricos e a museus; apreciação de imagens diversas (pinturas, gravuras, fotografias), eventualmente com a comparação entre situações e cenários do passado com os do presente; visitas a museus digitais; reprodução de locais e/ou situações históricas, com recursos de imersão graças à realidade virtual ou da utilização de videogames.

Esses recursos detêm elementos que permitem, além da valorização do lugar em que se vive e do legado de sua região, reconhecer a existência de espaços específicos de conservação da memória, tais como os museus. Essas experiências são capazes de mudar as perspectivas e ampliar os horizontes de conhecimento dos alunos, pois o contato e o diálogo com outras realidades, assim como a comparação da teoria com o que pode ser apreciado na "realidade" são potencializadores de aprendizado.

Dewey (1959) também argumentava que o passado, organizado em torno de uma narrativa de progresso social e intelectual, em um esquema organizacional para o currículo escolar, não atendia às necessidades de aprendizagem da disciplina de História. Os professores devem apresentar os fatos históricos somente quando apresentarem uma visão sobre a vida presente.

Fallace (2010) explica que na concepção de Dewey, para alcançar essa perspectiva da história, ao invés de relacionar o conteúdo da disciplina com fatos estáticos e pré-determinados, os professores precisam privilegiar um conjunto de simplificações de processos, desvendando e envolvendo problemas concretos e 
ferramentas correspondentes ao desenvolvimento da humanidade, alinhado com as fases de desenvolvimento da criança. Assim, a história da humanidade dita a seleção de conteúdos, e o nível de desenvolvimento da criança dita a forma adequada de transmissão desse conteúdo, como o último recapitulou o primeiro.

Para Dewey (1959), o currículo escolar necessita ser organizado como uma história reencenada e com episódios cuidadosamente escolhidos. Em relação à seleção de conteúdos, Dewey explicou que as fases do desenvolvimento histórico são essenciais para constituir a ordem existente. Sobre a organização deste conteúdo, ele considerava que a realização de um estudo de formas simples contribuiria para reduzir a complexidade dos conteúdos históricos.

A elaboração e apropriação de determinado conhecimento deve ser analisada a partir de suas características em dado tempo e espaço. Tratando-se especificamente da história, a compreensão das estruturas dos fatos históricos, objetos ou cenários são importantes para uma leitura do que ocorreu em determinada sociedade, buscandose, de algum modo, relacioná-la com o presente. Sem estas características, as relações de passado e presente podem ficar sem sentido ou gerar pouco interesse no aprendizado.

A compreensão sobre as estruturas processuais de uma narrativa histórica, de um fato ou de uma atividade didática em História necessita proporcionar o desenvolvimento do conhecimento humano de modo crítico-analítico. Entendemos que atividades pedagógicas que tenham essa premissa devem considerar uma perspectiva de pequena, média e longa duração acerca da observação dos fatos, construção e comparação de fontes e sua respectiva crítica. Portanto, o saber é, na realidade, produto de um emaranhado de vários processos de conhecimento historicamente construídos e constantemente revisados.

\section{Jogos: reflexões sob uma perspectiva deweyana}

De acordo com as concepções de Dewey (1971), no cenário norte-americano, assim como no de outros países, as tradicionais técnicas educacionais, centradas apenas na memorização de fatos, de datas ou em biografias isoladas de personagens históricos, geraram uma separação artificial entre a escola e a "vida real", sufocando 
a criatividade e impossibilitando a aprendizagem. Entretanto, se os educadores tomassem a experiência e a capacidade dos alunos como foco, seria possível romper a artificial separação entre a escola e a vida.

Para Dewey, tanto para os adultos quanto para as crianças, o desenvolvimento do pensamento é um recurso fundamental para a resolução de situações-problema que surgem no decorrer da experiência. Este desenvolvimento decorre de "um esforço consciente e voluntário, que se inicia pela observação e, consecutivamente, dá-se pela ordenação de hipóteses com necessárias intervenções, constituindo-se em instrumento destinado a resolver problemas" (HENZ; SANTOS; SIGNOR, 2018, p. 141). Sob esse viés, compreende-se o conhecimento, como a acumulação do saber gerado em decorrência da resolução desses problemas, pois “o conhecimento só pode se tornar significativo quando compõe experiências para o indivíduo" (HENZ; SANTOS; SIGNOR, 2018, p. 150)

Desse modo, ele incentivava "a autonomia e a liberdade de crianças e jovens na escola, esta pensada enquanto espaço de diálogo, vivências e possibilidades para novas e coletivas aprendizagens" (HENZ; SANTOS; SIGNOR, 2018, p. 150) e realçava a relevância do elemento ativo e impulsivo da criança no processo de aprendizagem. Contudo, "enfatizava a necessidade de combinar o enfoque ativo centrado nas capacidades infantis com o enfoque social do processo educativo" (RUIZ, 2013, p. 106, tradução nossa).

Para Dewey (1959), o saber e o fazer precisam estar apoiados na ideia de que o conhecimento resulta de algo mais elevado que a atividade prática e cotidiana. O conhecimento deve estar ligado a interesses práticos e aos sentidos. Nessa direção, os jogos podem proporcionar uma "experiência prática" (experiência simulada), permitindo ao indivíduo avaliar seu conhecimento sem que passe pela experiência real.

Com o aumento da oferta e do uso de tecnologias digitais, os jogos digitais podem contribuir significativamente para preencher a lacuna entre as experiências dos alunos e o domínio da escola, sobretudo nos conteúdos de História.

O jogo, com seus elementos em espaços diferenciados e potenciais de manuseio, configura-se em facilitador para a compreensão de conhecimentos. Entretanto, o simples ato de jogar, por si só, não garante a compreensão de um 
conteúdo. Para que sejam estabelecidas relações entre o jogo praticado e as informações oferecidas, tornam-se necessárias intervenções, podendo-se ponderar "que jogar requer um letramento específico que contribui para o desenvolvimento do "ato de questionar" e para construção de conhecimento" (PEDROSA, 2016, p. 92).

Dewey (1959) defendeu uma aprendizagem que possibilitasse o envolvimento do aluno, sendo considerada como uma experiência ativa e pessoal relevante para as experiências e capacidades do mesmo. Os jogos digitais oferecem aos alunos a oportunidade de experimentar a História por meio de uma atividade realizada no contexto familiar de um jogo de simulação, inserindo-os, desse modo, em um ambiente virtual de aprendizagem de conteúdos.

De acordo com Gee (2007), os jogos digitais têm sido analisados por especialistas educacionais devido aos potenciais que apresenta para o aprendizado. Entretanto, Gee (2008) argumenta que não considera qualquer jogo como eficiente e especula sobre o que haveria de pedagógico em um jogo.

É preciso pensar nos objetivos do jogo, quais os propósitos aos quais devemos nos ater ao elaborar as tarefas para o aluno, seus conhecimentos prévios e o que se espera que sejam capazes de aprender. Gee (2008) elenca condições para que um jogo contribua para a aprendizagem, de modo suscinto nos apropriamos de algumas delas.

Identidade: o aprendizado só ocorre quando há empatia e comprometimento. A personagem, construída ou manipulada, de acordo com as preferências de quem joga, deve proporcionar um ambiente palpável para a jogabilidade. Essa afinidade permite que o jogador tenha um desempenho superior.

Interação: a forma de interação jogo-jogador é importante, pois valoriza o princípio de pertencimento e evoca o jogador à relevância de suas ações que têm consequências, ou seja, o modo de ação e de tomada de decisões gera uma resposta no ambiente, levando o jogador para novas aventuras ou para desafios distintos. Portanto, não é possível assumir uma postura passiva.

Produção: em diversos jogos, os jogadores não são apenas consumidores, também são produtores, pois, mesmo em níveis mais simples, eles cocriam eventos dentro de um jogo, quer pelas ações que tomam, como por suas decisões. Alguns jogos permitem que extensões possam ser customizadas pelos seus usuários. Podemos destacar os jogos de aventuras on-line (os RPGs) como um dos principais 
ambientes que disponibilizam estas ferramentas. Assim, é importante a conscientização sobre a possibilidade de os jogadores poderem ajudar a "escrever" os mundos que eles vivem na escola e sobre "escrever" o domínio e o currículo que estudam. Pode-se, desse modo, observar que há diferentes caminhos para o alcance de um mesmo objetivo.

Tomada de riscos: os jogos são capazes de amenizar as consequências do fracasso, pois em muitos deles é possível recomeçar de onde ocorreu a decisão falha que gerou a decisão equivocada. Desse modo, incentiva-se a autonomia, prepara-se para a assunção de riscos pelas ações, exploração de novos recursos ou estratégias e a reflexão sobre o que impediu o alcance da meta ou da vitória, bem como o melhor aproveitamento de recursos.

Desempenho anterior à competência: segundo o autor, bons jogos operam por um princípio distinto do que observado nas escolas pois os jogadores podem performar, galgando diferentes níveis de dificuldade crescente, antes de serem excelentes naquilo que fazem. Neste conceito, salienta-se a importância da colaboração nas tarefas executadas, troca de informações, busca e interpretação do que está escrito, além do domínio das linguagens específicas do jogo, o que configura-se como aprendizado.

Os jogos digitais bem projetados, sobretudo os de simulação, oferecem, potencialmente, aos educadores um método possível para a promoção de aprendizagem autêntica que envolve o aluno em experiências de aprendizagem reais e significativas, expandidas para além das paredes da sala de aula.

O uso de jogos, por meio dos recursos gráficos, de enredos ou de jogabilidade, podem favorecer a aprendizagem autêntica, proposta por Dewey (1971), envolvendo e motivando os alunos com as habilidades tecnológicas essenciais para se tornarem conhecedores ativos consistentes com a finalidade da educação histórica. Ele acreditava que a ciência e a tecnologia poderiam contribuir para a modernização e o progresso da sociedade. Desse modo, pensar em uma escola capaz de potencializar o desenvolvimento de uma sociedade científica e aberta com ideais democráticos, além de associá-los com os saberes vivenciados na escola são possibilidades a serem trabalhadas e discutidas durante a elaboração curricular.

Apesar de suas inegáveis colaborações e de seus questionamentos em relação ao "extremismo metodológico e curricular", muitos dos conceitos teóricos de Dewey 
são qualificados como tecnicistas por julgar-se que ele "desconsiderou as relações de poder existentes no ambiente escolar, as contribuições da ciência e o desenvolvimento da criticidade, fazendo com que suas preposições fossem taxadas, no mais das vezes, como tecnicistas" (BRESOLIN, 2011, p.43).

\section{Considerações finais}

A filosofia deweyana tinha como proposta uma educação democrática na qual a igualdade de oportunidades fosse um elemento primordial, ou seja, independente das origens sociais ou econômicas. Cada aluno deveria enriquecer-se a partir das experiências dos outros, por meio da colaboração em tarefas propostas nas quais se aprende algum conhecimento por meio da prática.

Dewey acreditou, a partir do interesse do aluno, na reconstrução de experiências como fonte de uma pedagogia que privilegiasse esse aluno. Em suma, fazer uso do que o aluno já conhece e interagir com este saber, com o do professor e com o de outros alunos. Desse modo, a educação na concepção deweyana é vista como um processo contínuo de investigação, oriundo de problemas reais e de interesse para os alunos, que ao serem analisados e solucionados, geravam novos aprendizados capazes de sustentar outras investigações.

A construção de um currículo — que atendesse às propostas de uma escola aberta, democrática, científica, ativa e mutável — permitiria criar a necessária integração entre sujeito, objeto, natureza e espírito. Como uma construção coletiva, o currículo não assume uma forma linear de construção, pois embora tenha de respeitar às determinações e sanções legais, representa a história da escola e o que se espera construir com a sociedade na qual está inserida, ou seja, trata-se de um movimento contínuo, desenhado a partir do que a comunidade escolar almeja e necessita, sempre com sentido prático para os alunos.

Como visto, a influência do pensamento educacional e filosófico de Dewey foi usada para o embasamento de várias práticas educacionais em diversos países. No Brasil, o movimento dos pioneiros da Escola Nova, do qual participaram, entre outros, Anísio Teixeira, Fernando de Azevedo, Lourenço Filho, defendia um modelo de escola pública e laica, igualitária e sem privilégios. 
O estudo de História, orientado sob um prisma democrático, a partir da realidade e dos conhecimentos vivenciados pelos alunos, torna-se um grande e interessante desafio. Trazer os conhecimentos trabalhados em outros contextos históricos, compreender as relações de poder e realizações da sociedade, saber como um evento contemporâneo se desenvolveu e a importância de analisar fontes históricas são alguns dentre os componentes curriculares que podem ser trabalhados no ensino de História.

As formas de evocar e relacionar estes e outros conhecimentos dos domínios da História em tempos de tecnologias digitais, com apelo aos alunos, propicia amplas e instigantes oportunidades de se estabelecer uma relação com os conteúdos curriculares, de modo a torná-los mais atrativos, mais palpáveis e de melhor compreensão, seja por estímulos orais, visuais ou auditivos.

Atualmente possuímos diversas mídias que podem contribuir para a construção do conhecimento. Entre elas, incluem-se os jogos digitais, usualmente denominados videogames ou, simplesmente, games. Os jogos digitais vêm ganhando muitos adeptos ao longo do tempo e possuem ambientes - em sua maioria voltados para o puro entretenimento — nos quais tem-se contato com conteúdos e saberes que não são aqueles necessariamente ensinados nas escolas.

No entanto, como necessário em relação a qualquer outra fonte de aquisição de conhecimento, é fundamental observar as intencionalidades subjacentes ao jogo, especificamente, em nosso caso, quando trabalhamos conteúdos voltados para a História.

Uma metodologia voltada para os jogos digitais deve, obrigatoriamente, incluir cuidados tais como: contribuir com interesses alinhados com os conteúdos curriculares, atentar-se para classificação etária, avaliar a relevância para o aluno, permitir discussões sobre o que foi apresentado nos jogos, fomentar comparações com a realidade e, fundamentalmente, suscitar no aluno não apenas o desejo de jogálos, mas também seu interesse pela conjuntura histórica que o inspirou. Portanto, simular e construir são importantes fontes de incentivo às percepções humanas sobre um fato ou evento histórico.

Nos cenários atuais dos campos do ensino de História e das mudanças propostas pela Base Nacional Comum Curricular - BNCC (BRASIL, 2016), 
entramos em um campo nos quais teremos debates acirrados. Ainda são fortes as tendências ao engessamento do ensino, com uma abordagem restrita à da história linear que dificilmente desperta o interesse dos estudantes, dificultando sua compreensão e, consequentemente, impedindo que lhe seja dada a devida significação.

As principais críticas à BNCC (BRASIL, 2016) versam sobre os saltos temporais excessivos no diálogo entre os conteúdos, estruturação de habilidades descompassadas com as reais, esperadas dos alunos, e anacronismo quanto à localização do sujeito na sua atualidade, especificamente em relação ao Brasil. Este último item pode ser considerado um ponto crítico, pois os conteúdos sobre história apresentados aos alunos do ensino fundamental nas séries finais são disponibilizados de modo genérico, ou seja, sem aprofundamento ou referências locais. Além disso, pode-se evidenciar uma ruptura quando não são abordados os tempos mais recentes da história brasileira (CAIMI, 2016; MALERBA, 2017).

De acordo com Caimi (2016), além dos desafios de se propor uma base comum a um território tão diferenciado em valores regionais, culturais e com um território extenso, a formulação da BNCC conta com propostas realizadas por grupos distintos, que não procuraram dar segmento ao trabalho dos antecessores.

Os pressupostos de Caimi (2016) alertam sobre a retomada de uma visão linear da história, desconsiderando os postulados das pesquisas acadêmicas nos últimos 30 anos, enquanto Malerba (2017) ressalta que a compreensão da história, segundo o documento, tende a incentivar como cronologia de eventos históricos.

Nesse contexto, a perspectiva de Dewey convida à reavaliação das formas de ensino que estão ocorrendo no Brasil e do que é necessário repensar para que os alunos participem e sejam membros vivos da História.

Hora de "apertar o start"?

\section{Referências}

BRASIL. Ministério da Educação. Secretaria da Educação Básica. Base nacional comum curricular. Brasília, DF, 2016. Disponível em: <http://basenacionalcomum.mec.gov.br/\#/site/inicio>. Acesso em: 20 dez. 2018. 
BARROS, J. C .A. A Escola dos Annales: considerações sobre a História do Movimento. Revista Eletrônica História em Reflexão, Dourados, v. 4, n. 8, dez. 2010. Disponível em: $<$ http://ojs.ufgd.edu.br/index.php/historiaemreflexao/article/view/953/588>. Acesso em: 23 fev. 2019.

BRESOLIN, A. R. O professor de línguas em formação: uma experiência reflexiva com blog. Dissertação (Mestrado em Estudos de Linguagem) - Universidade Federal de Mato Grosso, Instituto de Linguagens, Pós-Graduação em Estudos de Linguagem, 2011.

BURKE, P. Abertura: a nova história, seu passado e seu futuro. In: BURKE, P. (Org) $A$ escrita da história: novas perspectivas. São Paulo: Unesp, 1992.

CAIMI, F. E. A História na Base Nacional Comum Curricular: pluralismo de ideias ou guerra de narrativas?. Revista do Lhiste-Laboratório de Ensino de História e Educação, v. 3, n. 4, 2016. Disponível em: <https://seer.ufrgs.br/revistadolhiste/article/view/65515> Acesso em: 20 mar. 2019.

DEWEY, J. Como Pensamos. Como se relaciona o pensamento reflexivo com o processo educativo: uma reexposição. São Paulo: Editora Nacional, 1933.

DEWEY, J. Reconstrução em Filosofia. São Paulo: Companhia Editora Nacional, 1958.

DEWEY, J. Democracia e Educação. São Paulo: Companhia Editora Nacional, 1959.

DEWEY, J. Experiência e Educação. São Paulo: Companhia Editora Nacional, 1971.

DEWEY, J. Vida e educação. Tradução e estudo preliminar por Anísio S. Teixeira. São Paulo: Melhoramentos; Rio de Janeiro: Fundação Nacional de Material Escolar, 1978.

FALLACE, T. D. John Dewey on history education and the historical method. E\&C/EducationeCulture, v. 26, n. 2, p. 20-35, 2010. Disponível em: <https://docs.lib.purdue.edu/eandc/vol26/iss2/art4/> Acesso em: 17 jan. 2019.

GARCIA, J. Escritos sobre o currículo escolar. São Paulo: Iglu, 2010.

GEE, J. P. What video games have to teach us about learning and literacy. New York: Macmillan, 2007.

GEE, J. P. Good video games and good learning. New York: Peter Lang, 2008.

HENZ, C. I.; SANTOS, C. A.; SIGNOR, P. Experiência e movimento: pensando a educação em Dewey. Espaço Pedagógico v. 25, n. 1, Passo Fundo, p. 140-152, jan./abr. 2018. Disponível em: <http://dx.doi.org/10.5335/rep.v25i1.8036> Acesso em: 12 abr. 2018.

MALERBA, J. Uma análise da Base Nacional Comum Curricular. 2017. Disponível em: $<$ https://www.cafehistoria.com.br/uma-analise-da-base-nacional-comum-curricular/ $>$. Acesso em: 20 mar. 2019.

OELKERS, J. John Dewey e a refutação do pensamento educacional clássico. Espaço Pedagógico. v. 25, n. 1, Passo Fundo, p. 9-21, jan./abr. 2018. Disponível em: <http://dx.doi.org/10.5335/rep.v25i1.8029> Acesso em: 12 abr. 2018. 
PEDROSA, S. M. P. A. Pensando com e sobre games. Revista Educação e Cultura Contemporânea. v. 13 n. 31, p. 83-100, 2016. Disponível em: <http://periodicos.estacio.br/index.php/reeduc/article/viewArticle/1964 Acesso em: 12 fev. 2019.

REIS, J. C. Nouvelle Histoire e o Tempo Histórico. A contribuição de Febvre, Bloch e Braudel. $2^{\mathrm{a}}$ ed. São Paulo: Annablume, 2008.

RUIZ, G. La teoría de la experiencia de John Dewey: significación histórica y vigencia en el debate teórico contemporáneo. Foro de Educación, v. 11, n. 15, p. 103-124, 2013. Disponível em: <http://dx.doi.org/10.14516/fde.2013.011.015.005> Acesso em: 10 jan.2019.

SILVA, M. R. Perspectivas Curriculares Contemporâneas. Curitiba: Ibpex, 2012

SOUZA, R. A.; MARTINELLI, T. A. P. Considerações históricas sobre a influência de John Dewey no Pensamento Pedagógico Brasileiro. Revista HISTEDBR, Campinas, n. 35, p. 160 162, set. 2009. Disponível em <https://periodicos.sbu.unicamp.br/ojs/index.php/histedbr/article/view/8639620/718>. Acesso em 12 fev. 2019.

SOUZA, R; MACHADO, M. A concepção de história na pedagogia de John Dewey. Cadernos da Pedagogia, São Carlos, v. 3, n. 6, p. 104-113, jul.-dez. 2009. Disponível em: http://www.cadernosdapedagogia.ufscar.br/index.php/cp/article/view/165/90. Acesso: em: 12 fev. 2019. 